\title{
急性期内頸動脈塞栓症に対する傍塞栓線溶療法
}

鈴木 泰篤 川俣光 松 本 清*

\section{Central Intraarterial Fibrinolysis for Acute Embolic Stroke of the Internal Carotid Artery \\ by}

Yasuhiro Suzuki, M.D., Teru Kawamata, M.D., and Kiyoshi Matsumoto, M.D.*

from

Department of Neurosurgery, Chibanishi General Hospital, and

*Department of Neurosurgery, Showa University School of Medicine

\begin{abstract}
Local fibrinolysis can achieve favorable results in patients with occlusion of the middle cerebral artery, but the outcome is still poor or sometimes fatal in patients with occlusion of the internal carotid artery. Central intraarterial fibrinolysis $(\mathrm{CIF})$ is often performed to treat occlusion of the middle cerebral artery. However, the guidewire and microcatheter are generally difficult to pass beyond the embolus causing occlusion of the internal carotid artery. A double angle-shaped guidewire enabled us to introduce CIF for embolic occlusion of the internal carotid artery. The technique is briefly summarized as follows: The radiforcus GT guidewire is passed between the embolus and the vascular wall; the tip of the guidewire is then reversed, and the microcatheter is advanced until the tip is just distal to the embolus; infusion of the fibrinolytic agent is then initiated to dissolve the embolus from the distal side. Recanalization was achieved in 5 of the 6 patients. This technique is useful for both CIF and percutaneous transluminal angioplasty.
\end{abstract}

(Received November 19, 1997; accepted December 17, 1998)

Key words : cerebral embolism, internal carotid artery, central fibrinolysis, intraarterial fibrinolysis

Jpn J Neurosurg (Tokyo) 8: 459-463, 1999

はじめに

内頸動脈閉塞症，特に内頸動脈塞栓症では急性期局所 線溶療法の再開通率が低く, 予後不良となるケースが多 い. 中大脳動脈閉塞症の治療に効果的な傍塞栓線溶療法 (central intraarterial fibrinolysis; $\mathrm{CIF})^{1)}$ p経皮的血管 形成術 (percutaneous transluminal angioplasty; PTA)も, 内頸動脈塞栓症では閉塞部位を越えてガイド ワイヤーを末梢まで導くことがむずかしく，本症には効 果的な治療法とはなっていない。われわれはダブルアン グル型ガイドワイヤーを使用することで，内頸動脈塞栓 症に対しCIF を可能にしたので報告する。

\section{対象および方法}

\section{1 対 象}

対象は来院時頭部 CT で虚血性変化がまだ出現してい ない急性発症の内頸動脈塞栓症 6 例（男性 1 例, 女性 5 例, 35〜73 歳, 平均 64.5 歳) である. 全例心疾患の既 往を有しており，来院時心電図で心房細動を認めた。ま た発症状況, 血管撮影の閉塞所見なども踏まえ, 塞栓症 と判断した。脳血管撮影により発症より 2 時間以内に閉 塞部位を確認し, また 4-vessel study を行い, 前交通 動脈と後交通動脈を介する側副血行路が不良であること も確認した。 rCBF の測定は行えなかった。

千葉西総合病院脳神経外科〔連絡先：鈴木泰篤，テ $274-0053$ 船橋市豊富町 696-1 セコメディック病院脳神経外科〕

Address reprint requests to: Yasuhiro Suzuki, M.D., Department of Neurosurgery, SECOMEDIC Hospital, 696-1

Toyotomi-machi, Funabashi-shi, Chiba 274-0053, Japan

*昭和大学医学部脳神経外科 


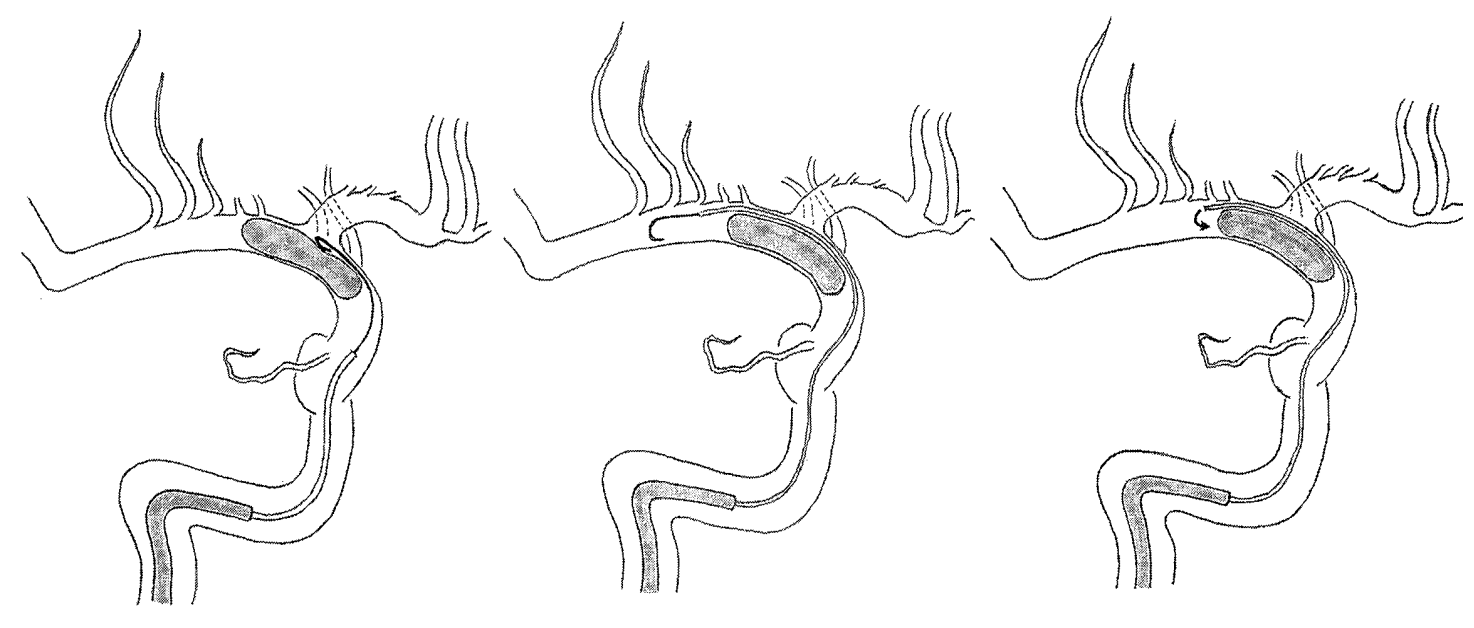

$\overline{\mathrm{A}|\mathbf{B}| \mathrm{C}}$ Fig. 1 Schematic presentation of the technique of central intraarterial fibrinolysis for embolic occlusion of the right internal carotid artery

A, B : Double angle-shaped guidewire/microcatheter system is passed between the embolus and the vascular wall.

C : The tip of the catheter is placed just distal to the embolus, when injection of a fibrinolytic agent is initiated to dissolve the embolus from the distal side.

Table 1 Case summary

\begin{tabular}{|c|c|c|c|c|c|c|c|c|}
\hline Case & Age & Sex & $\begin{array}{c}\text { JCS on } \\
\text { admission }\end{array}$ & $\begin{array}{c}\text { Site of } \\
\text { occlusion }\end{array}$ & $\begin{array}{c}\text { Recanalization } \\
\text { (hours) }\end{array}$ & $\begin{array}{l}\text { t-PA dose } \\
\left(\times 10^{5} \mathrm{U}\right)\end{array}$ & Post CT (LDA) & Outcome \\
\hline 1. C.N & 71 & $\mathrm{~F}$ & $I-3$ & $\mathrm{C} 4$ & $\operatorname{partial}(2)$ & 32 & $\mathrm{C}$, large & $\mathrm{MD}$ \\
\hline 2. K.K & 69 & $\mathrm{~F}$ & II -1 & $\mathrm{C} 3$ & $(-)$ & 24 & $\mathrm{C}+\mathrm{B}$, medium & MD \\
\hline 3. S.N & 73 & $\mathrm{~F}$ & III-1 & $\mathrm{C} 2$ & partial (3) & 16 & $\mathrm{C}+\mathrm{B}$, large & VS \\
\hline 4. M.M & 71 & M & I -3 & $\mathrm{C} 2$ & partial (4) & 16 & $\mathrm{C}$, medium & $\mathrm{MD}$ \\
\hline 5. T.Y & 35 & $\mathrm{~F}$ & III-1 & $\mathrm{C} 2$ & partial (3) & 32 & $\mathrm{C}$, medium & $\mathrm{SD}$ \\
\hline 6. Y.E & 68 & $\mathrm{~F}$ & $\mathrm{I}-3$ & $\mathrm{C} 2$ & partial (4) & 32 & $\mathrm{C}$, medium & GR \\
\hline
\end{tabular}

JCS: Japan Coma Scale C2: cisternal portion $\quad$ C3: anterior knee $\quad$ C4: cavernous portion LDA: low density area $\quad \mathrm{C}$ : cortical low density area $\mathrm{B}$ : low density area of basal ganglia $\mathrm{MD}$ : moderate disability VS: vegetative state $\mathrm{SD}$ : severe disability GR: good recovery

\section{2 方 法}

まず撮影に使用した親カテーテル（グランドキャッス II Fr.5R)をできるだけ高位（できれば petrosal portion）まで上げる. 次にマイクロカテーテル（ジェット ストリーム 18 ハイライトR) とガイドワイヤー（ラジ フォーカス $\mathrm{R}$ ガイドワイヤー $\mathrm{M}$ ダブルアングル型, 外 径 0.016 インチ, 先端アングル $90^{\circ}+150^{\circ}$ ）を閉塞部位 に誘導する.ガイドワイヤーを栓子と血管壁の間を通し て閉塞部位より末梢へ進める（Fig. 1A）。この時ガイド ワイヤーの先端は反転した状態になっている，通過時先 端の抵抗を感知しながら慎重に進めていき，進みにくい 時は少し引いてトルクをかけてから再度進める。栓子部 を通り過ぎるとガイドワイヤーが楽に動くようになり， 塞栓の遠位端を知ることができる．続いてマイクロカテ ーテルを通過させ (Fig. 1B)，ガイドワイヤーを抜き，
生食 $100 \mathrm{~m} l$ に溶解した t-PA 160〜320万単位を 30 分 程度かけて動注しながらマイクロカテーテルを引き，末 梢から溶解していく（Fig. 1C).

\section{結 果}

閉塞部位は, cavernous portion と anterior knee が 各 1 例で，4 例は cisternal portionであった。閉塞部位 の遠位端は確認できなかったため, 中大脳動脈水平部の 遠位より溶解を開始した。発症から治療終了までの時間 は 4 時間以内で，6例中 5 例に部分再開通が得られた (Table 1)。この5 例は基底核部や皮質領域に比較的広 範な虚血性変化を起こし，1例に減圧開頭術を追加し た。しかし実際に虚血性変化を起こした領域は, 内頸動 脈あるいは中大脳動脈の灌流領域から予想される虚血範 

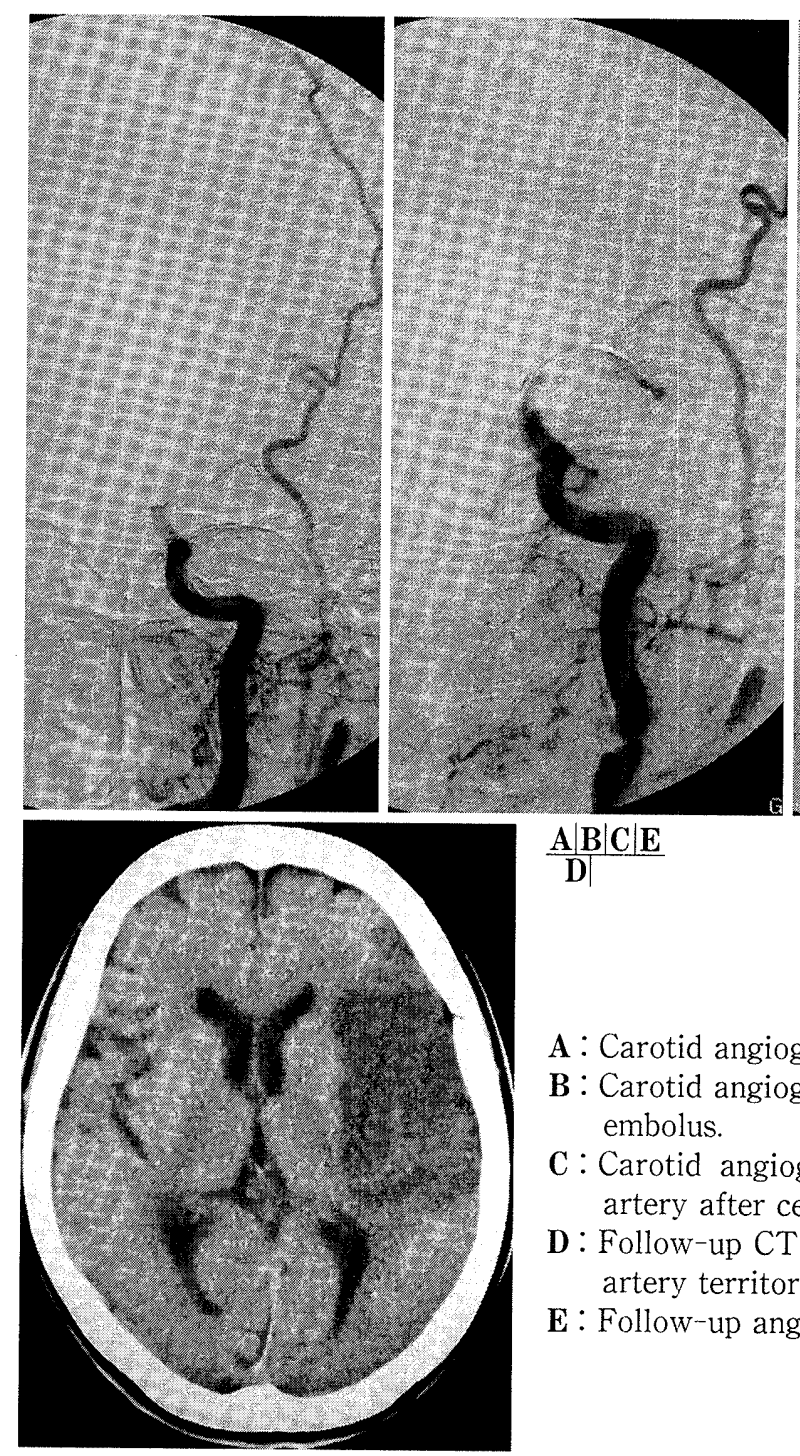

$\frac{\mathrm{A}|\mathbf{B}| \mathbf{C} \mid \mathbf{E}}{\mathrm{D} \mid}$
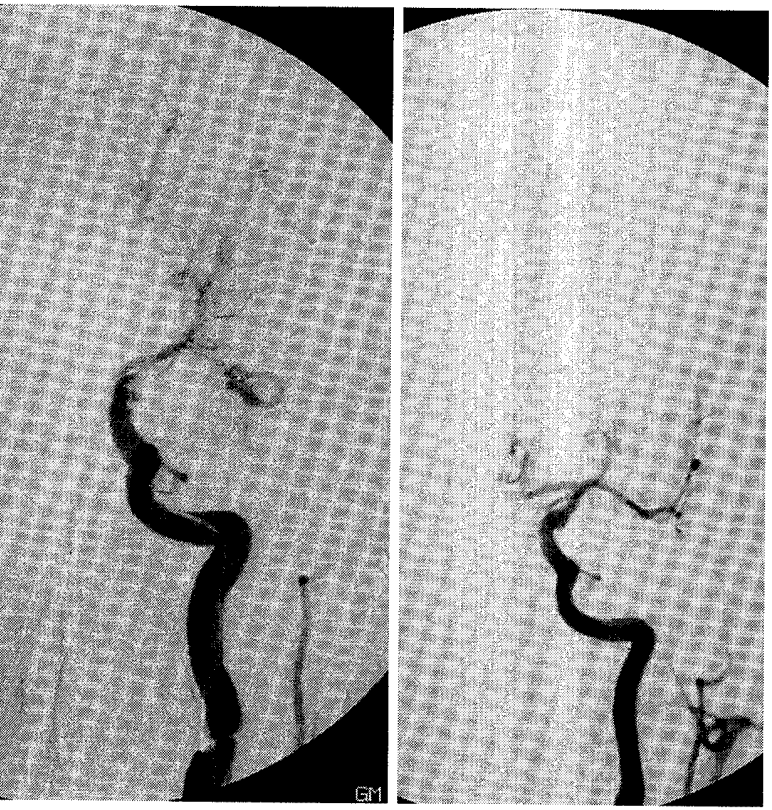

Fig. 2 Case 6

A : Carotid angiogram shows occlusion of the left internal carotid artery.

B : Carotid angiogram shows the tip of the microcatheter located distal to the embolus.

C: Carotid angiogram shows partial recanalization of the internal carotid artery after central arterial injection of t-PA (3,200,000 units).

D : Follow-up CT scan shows moderate infarction in the left middle cerebral artery territory.

E: Follow-up angiogram shows complete recanalization.

囲と比較し，明らかに限局された範囲にとどまってい た. 予後は good recovery (GR) が1例, moderate disability (MD) が 3 例, severe disability (SD) が 1 例, 再開通しなかった 1 例は 2 力月ほど遷延性意識障害 で経過した後肺炎で死亡した.SDの1例は減圧開頭を 要した症例であり, 過去に対側の中大脳動脈塞栓症を起 こしていた。再開通した 5 例は 1 週間以内に脳血管撮影 を再度行い，ほぼ完全に再開通していることを確認した (Table 1).

\section{症 例}

患 者：68 歳, 女性（Table 1, Case 6)

主 訴: 意識障害, 右片麻焷

既往歴: 不整脈 (Af) にて当院循環器科通院中.

現病歴：1997 年 11 月 23 日午前 11 時頃, 自宅で家事 の最中気分不快を訴えたため救急車をよび，30 分後に
来院した。

来院時所見：意識レベル JCS I-3，右片麻疩（徒手筋 カテストで上肢 $4 / 5$ ，下肢 $4 / 5$ ）を認めた。血圧 $178 / 96$ $\mathrm{mmHg}$, 脈拍 $112 /$ 分, 脈不整あり.

経 過：CTでは異常を認めず，緊急脳血管撮影を施 行した. 左内頸動脈 cisternal portion の閉塞を認めた ため (Fig. 2A), 続いて CIF を施行した (Fig. 2B). 術 後閉塞部位の一部再開通は得られたが (Fig. 2C), 皮質 領域に虚血性変化が出現した (Fig. 2D). 3 日後の血管 撮影では完全再開通が得られていた (Fig. 2E). その後 麻痺は著明に改善し, 1 力月後軽度の失語症を残し GR の状態で独歩退院した。

\section{考 察}

内頸動脈塞栓症は側副血行路が発達していない場合, 一般にはきわめて予後不良であり, また通常の局所線溶 療法では治療成績も不良であるため6), 血管内治療の適 応から除外している施設もある。しかし，われわれはそ 
のような症例に対しても治療効果をあげ，予後の改善を 図るべく努力してきた，今回この方法で 6 例中 5 例に部 分再開通させることができた。これらは distal embolism による基底核や皮質領域の梗塞の発生はあるもの の，1例に GR，3 例に MD の予後を得ている.

閉塞部位の末梢から線溶療法を行う方法は，Zeumer ら6)により最初に報告されたものである。彼らは，カテ ーテルを中大脳動脈を閉塞した栓子と血管壁との間を通 して末梢へ進めることは可能であるとし，カテーテルの 先端を中大脳動脈の壁と塞栓の間においた場合，再開通 率は $80 \%$ であったと報告している7)。この方法により 後藤ら ${ }^{1)}$, 津波 ${ }^{4)}$, 松本 $ら^{2)}$ は中大脳動脈閉塞症に対 乙局所線溶療法を行い，良好な結果を得ており，後藤 ら1)はこの方法を central intraarterial fibrinolysis（傍 塞栓線溶療法）とよんでいる.

一般に内頸動脈閉塞症は中大脳動脈閉塞症に比べ，局 所線溶療法の再開通率は不良であり，特に塞栓性閉塞で はその傾向が強い6). 急性期局所線溶療法を行う場合, 効率よく再開通させる手技として CIF や線溶療法のみ で再開通が得られない場合に行う rescue PTAなどが あるが3)，これらを行うにはガイドワイヤーをいったん 閉塞部位の末梢まで進める必要がある。しかし内頸動脈 塞栓症では栓子が硬く，長い範囲に存在する傾向にある ため，ガイドワイヤーやカテーテルを末梢まで進めるこ とがむずかしい．また無理な力を加えることで血管壁の 損傷や穿通を招く恐れもあり，中大脳動脈閉塞症に対し て行うほど容易ではない。われわれの使用したガイドワ イヤーは先端がダブルアングル型となっているため, 閉 塞部位を通過する時，先端部が反転した状態になってい る. 通過時先端の抵抗を感知しながら慎重に進めてい き，進みにくい時は少し引いて，トルクをかけてから再 度進めることで閉塞部位を越えることが可能であった。

また， distal embolismによる脳梗塞は避けられなか ったが，梗塞の範囲を縮小させることができた．今回の 検討では来院時に意識レベルが JCS III-1であった症例 3，5が予後も不良となった。したがって $\mathrm{rCBF}$ の測定 が行われない場合には, 来院時意識レベルが JCS II 程 度までの症例に選択してみる価值のある方法ではないか と思われた。この方法はガイドワイヤーを進める際, 血 管壁の損傷や穿通などには十分な注意が必要であるが,
内頸動脈塞栓症に対しても末梢からの効率的な栓子溶解 ができまた rescue PTA や線溶療法を併用しない direct PTA ${ }^{5)}$ へも利用できることから, 今後症例を重 ねて検討してみるべき手技と考えられた。

\section{結 語}

内頸動脈塞栓症に対しダブルアングル型のガイドワイ ヤーを使用することで傍塞栓線溶療法を行い，6例中 5 例に再開通を得た。この手技により栓子を効率よく溶解 することができるとともに，PTAを行う際にも応用で きるものと考えられた。ガイドワイヤーを進める際，血 管壁の損傷や穿通などに対し十分な注意が必要である が，栓子を効果的に溶解する手技として選択してみるべ き方法の一つではないかと思われた。

\section{文 献}

1) 後藤勝弥, 清末一路, 緒方 登: 脳梗塞と血管内的アプ ローチによる治療. 田川晧一, 藤井清孝編: 脳卒中治療 学. 新潟, 西村書店, 1996, pp. 85-91.

2）松本祐蔵，目黒俊成，河田幸波，萬代眞哉，合田雄二, 守山英二, 櫻井 勝: 中大脳動脈閉塞症の治療と問題 点.脳卒中の外科 $23: 405-411,1995$.

3）須賀俊博，渡辺徹雄，渡辺美喜雄，大和田雅信，千葉明 善, 吉岡邦浩, 細矢貴亮：Rescue PTA おるび deferred PTA による段階的血管拡張が奏効した急性期 頸部内頸動脈閉塞症の 1例。脳外 24:1101-1106, 1996.

4）津波 満, 後藤勝弥, 緒方 登, 岩淵 聡, 武智昭彦, 井上亭, 松野治雄: Central intraarterial thrombolysis(傍塞栓線溶療法)の経験一その技術的側面を中 心に. 脳卒中の外科 21: 293-298, 1993.

5) Uno J, Fujita Y, Nishizaki J, Satoh T, Yoshizumi H: Fibrinolytic therapy and direct PTA for acute ischemic stroke. in Taki W, Picard L, Kikuchi H (eds): Advances in Interventional Neuroradiology and intravascular Neurosurgery. International Congress on Interventional Neuroradiology and Intravascular Neurosurgery, Kyoto, Japan, 1996, pp. 491-495.

6) Zeumer H, Hündgen R, Ferbert A, Ringelstein EB: Local intraarterial fibrinolytic therapy in inaccessible internal carotid occlusion. Neuroradiology 26:315317, 1984.

7) Zeumer H, Freitag HJ, Grzyska U, Neunzig HP: Local intraarterial fibrinolysis in acute vertebrobasilar occlusion: Technical developments and recent results. Neuroradiology 31:336-340, 1989. 
要旨

急性期内頸動脈塞栓症に対する傍塞栓線溶療法

鈴木 泰篤 川俣 光 松本 清

一般に内頸動脈塞栓症は中大脳動脈塞栓症に比べ，局所線溶療法による再開通率が低いといわれ る. われわれは先端がタフブルアングル型のガイドワイヤーを使用することで, マイフロカテーテルを 閉塞部位の遠位端を越えて未梢へ導き，末梢から栓子を溶解する傍塞栓線溶療法を行つている．この 手技により 6 例中 5 例に対し再開通を得ることができた. この手技は栓子を効率的に溶解できるとと もに，急性期内頸動脈塞栓症に対し経皮的血管形成術を行う際にも応用できるものと考えられた。

脳外誌 $8: 459-463,1999$ 